\title{
Mechanical Properties and Microstructure Improvement of a Two-Step Strain Induced Melt Activation Processed 7075 Aluminum Alloy Compared to that SIMA
}

\author{
Process \\ Mostafa Karamouz $^{* 1}$, Mostafa Alizadeh ${ }^{1}$, Ali Reza. Ahmadi ${ }^{2}$ \\ ${ }^{1}$ Department of Metals, Institute of Science and High Technology and Environmental Sciences, \\ ${ }^{2}$ Mechanical Engineering, Graduate University of Advanced Technology, PO Box 76315-115, Kerman, Iran
}

\begin{abstract}
Strain induced melt activation process (SIMA) creates a globular microstructure which improves the hardness and ultimate tensile stress (UTS) of 7075 aluminum alloys. But, at the grain boundaries of SIMA processed 7075 aluminum alloy, presence of continuous and brittle intermetallic compounds and the eutectic structure result in decreasing mechanical properties, such as elongation, formability and etc. Hence, in order to improve microstructure and formability of 7075 aluminum alloy respect to SIMA process, a new process was done that is called two-step strain induced melt activation (TSSIMA). This process, which has been mentioned in the experimental procedure section, both organized globular structure and significantly modified the microstructure of the alloy compared to that of the SIMA method. It promoted discontinuity and more homogeneity in distribution of the precipitates and, approximately removed the eutectic mixture. Performing the rolling process on the alloy also revealed that it is more effective in formability enhancement in comparison with SIMA process. Also, it increased the hardness of 7075 aluminum alloy respect to that of SIMA process.
\end{abstract}

Keywords: 7075 Aluminum alloy; eutectic mixture; formability; hardness.

\footnotetext{
${ }^{*}$ Corresponding author Tel/Fax/Mobile: +983426226611/+983426226617/+989196275936

E-mail: ravari@alumni.ut.ac.ir
} 


\section{Introduction}

Semi-Solid Forming (SSF) is a novel technology in forming near net shape components in the 21st century, offering several potential advantages over conventional casting and forging technologies such as high product quality and low forming efforts [1-4]. Many methods such as mechanical or electromagnetic stirring, the addition of grain refining elements, and cooling slope are used to obtain globular structures [5-7]. The employed techniques for obtaining the mentioned non-dendritic microstructure can be called microstructural conditioning or simply conditioning [8]. Among the production methods, Strain induced melt activating method (SIMA) is an ideal candidate with significant commercial advantages of simplicity and low equipment costs[1,9]. SIMA process consists of four discrete stages. First the alloy is cast in convenient sizes to obtain a typical dendritic microstructure. Subsequently, it is hot worked so a directional microstructure is introduced and the thickness of the casting is decreased. The third stage involves the introduction of a critical level of stored energy in the alloy by cold working. Finally, the deformed alloy is semisolid partially remelted, and held isothermally for a short time. In SIMA, the strain is introduced into the materials through predeformation $[9,10]$. In a general point of view, during soaking, recrystallization takes place, and once the liquid starts to form, grain boundaries are wetted and penetrated by it, leading to formation of fine equiaxed particles $[11,12]$. Deformation step can be carried out by some different procedures such as rolling, forging, upsetting and extrusion. All these methods have some restrictions in amount and homogeneity of the strain that can be induced in each pass. Some new technologies are under development that do not have these restrictions and can be used as commercial and engineering applications[13]. It was well showed that in the SIMA process increasing the globalizing temperature increases the amount of the liquid at the grain boundaries. Due to the effects of 
surface tension and interface curvature, the convex edges of the dendrites melt and decrease the interface area of the dendrites leading to a lower free energy. Moreover, concentration of the solute in the concave parts of the grains is higher, which increases the amount of the liquid in these areas. When the liquid of the two concaves contacted with each other, the grains would separate into autonomous small grains. It should be noted that increasing the heat treatment temperature causes a further dissolution of the eutectics and spheroidization of the $\alpha$-Al grains. At the temperatures higher than the eutectic temperature, the eutectic phase dissolves completely and the atoms diffuse into the $\alpha$-Al grains due to increasing of the diffusion capacity and solubility of the elements in $\alpha$-Al at higher temperatures. Since the second arms are small, they coarsen, combine and disappear when the eutectics between them are melted completely [13,14]. Amir Bolouri and et.al showed an increase in the level of the major alloying elements at grain boundaries and entrapped liquid droplets. They also indicated presence of $\mathrm{ZnCu}$-rich eutectic phase at grain boundaries that result in decreasing mechanical properties specially flexibility $[15]$.

Concept of this research is development of a new method for synthesis of globular structure and elimination of the eutectic mixture in 7075 aluminum alloy as well as improvement of its hardness and formability, respect to other synthesis process of globular structure such as: SIMA process.

\section{Experimental procedure}

Strips of $7075 \mathrm{Al}$ alloy were used in this investigation. The composition of the starting material is given in Table. 1. The annealed work pieces with the dimensions of 20X100X6 mm were machined from the slab, and then rolled to $30 \%$ reduction in thickness using a rolling instrument. 
After the rolling process, two different processes were administered, as shown in Fig.1. As shown in Fig.1a, in process 1, the rolled specimens were heated in an electrical resistance furnace up to $590{ }^{\circ} \mathrm{C}$ (semi-solid state) for periods of 5, 10 and 15 minutes and then cooled to $500^{\circ} \mathrm{C}$ at a constant cooling rate of $2^{\circ} \mathrm{C} / \mathrm{min}$ followed by quenching in cold water. The last stage of previous process was repeated once more without implementation of the pre-deformation, this process is called two-step strain induced melt activation (TSSIMA). In process 2 (strain induced melt activation (SIMA)), the rolled specimen was heated up to $590{ }^{\circ} \mathrm{C}$ for a period of 20 minutes (optimum holding temperature and time was selected based on reference[16]) then it was quickly quenched into cold water. These specimens were then mechanically polished and chemically etched in Keller reagent and their microstructures were observed through a Leisa DMLM optical microscope. The average grain size and shape factor of the grains were measured using Clemex Advantage Image Analysis software (Clemex Vision Pro. Ver.3.5.025). The calculations of average grain sizes were according to ASTM: E-112. The best holding time of the TSSIMA was determined by them.

Table. 1. Chemical composition of 7075 based aluminum alloy (wt.\%).

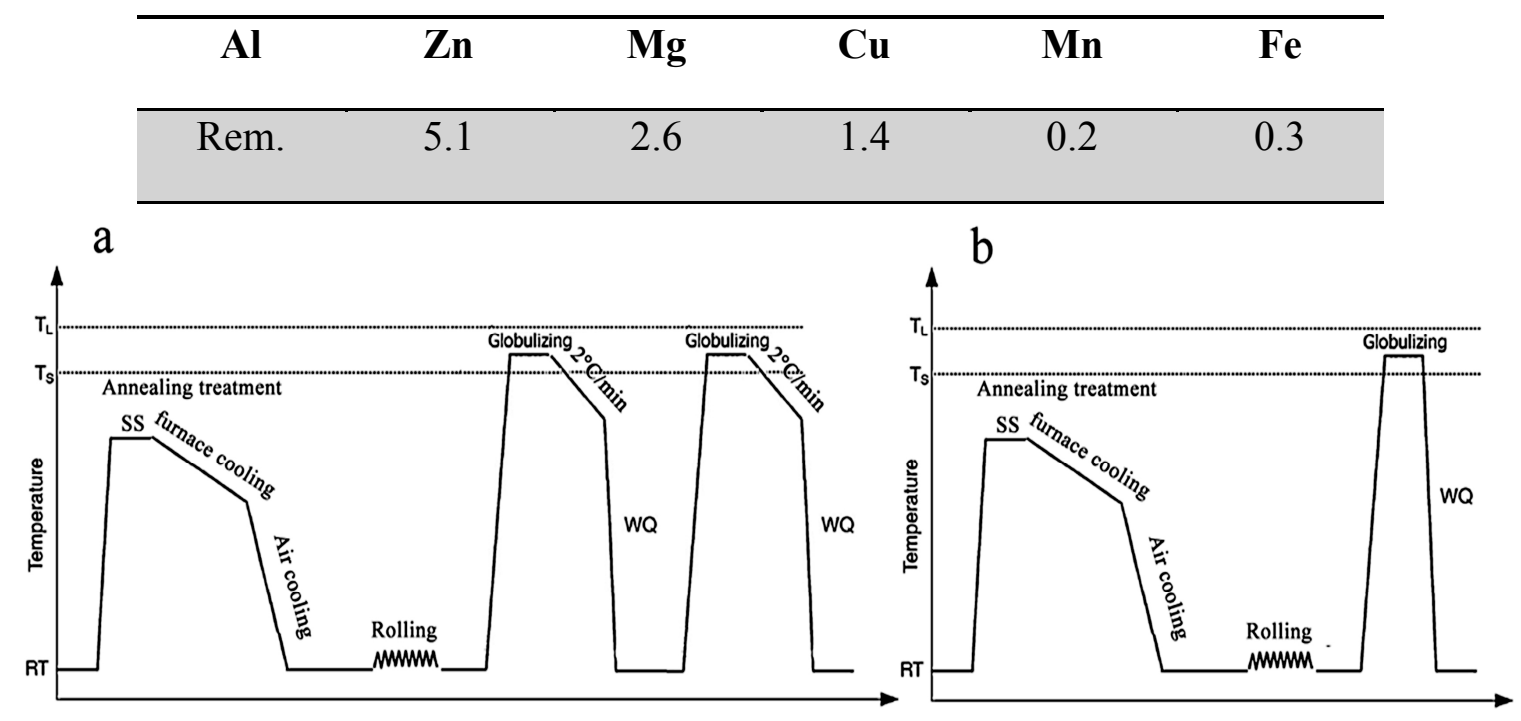

Fig. 1. Schematic illustrations of two processes: a) TSSIMA, b) SIMA. 
Further microstructural observations were carried out by a scanning electron microscope (SEM, Cam Scan MV2300) equipped with an energy dispersive X-ray analysis (EDX) accessory.

For formability test, the obtained specimens of the two processes were rolled to $30 \%$ reduction in thickness and captured by Leica Q550 MW. Hardness tests were carried out according to ASTM: E-384 using an Eseway tester (vickers hardness: $1 \mathrm{~kg}$ force). The samples were first surface finished and at least five measurements were performed randomly in each sample and averaged to obtain the accurate hardness of the specimens

\section{Results and discussion}

\subsection{Liquid fraction versus temperature}

A curve of 7075 aluminum alloy for liquid fraction versus temperature derived from the DSC result is shown in Fig. 2[17]. Based on this figure, at $590{ }^{\circ} \mathrm{C}$, the liquid volume fraction of the used alloy in this study is approximately $12 \%$.

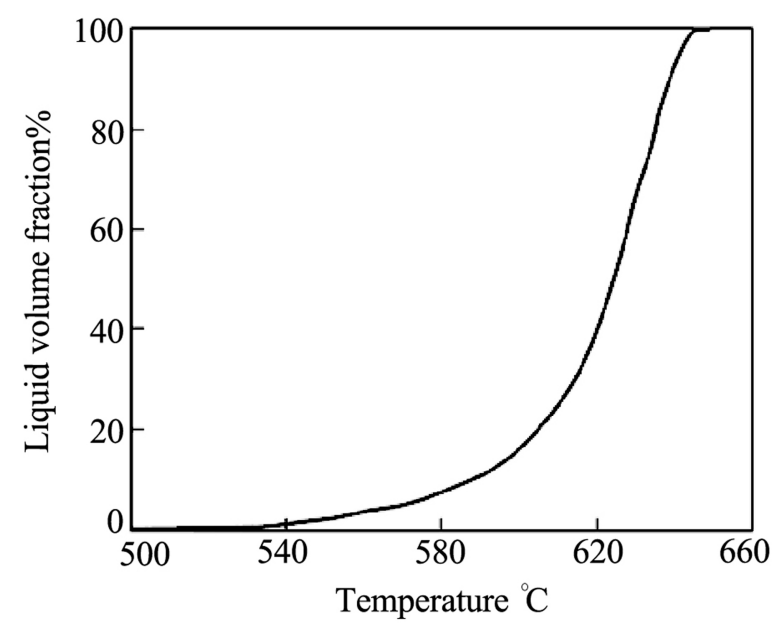

Fig. 2. Liquid fraction vs temperature of 7075 aluminum alloy estimated from DSC heating curves[17]. 


\subsection{Characterization of TSSIMA}

An optical micrograph for the annealed 7075 aluminum alloy is shown in Fig. 3. The microstructure consisted of unrecrystallised grains with various small dispersed particles, which are characteristics of such alloy.

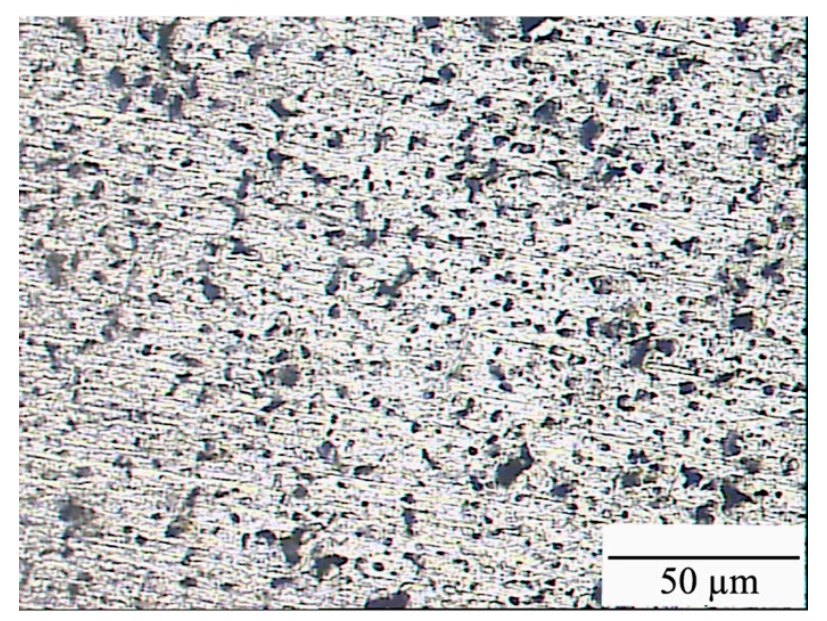

Fig. 3. Optical micrograph for annealed 7075 aluminum alloy.

Fig.4 shows the microstructures of specimens after applying different holding times during TSSIMA. From Fig.4b, it is clear that they have fine and uniform structures which are held for $10 \mathrm{~min}$. It is expected that at short holding times, most of the solid particles still congregate together and fragmentation does not completely occur (Fig.4a). With prolonging the holding time, the thickness of the liquid film increases remarkably and the solid particles are spherodized significantly and separate into finer ones as shown in Fig.4b. Moreover, Grain coarsening also occurs at longer times (15 min), as shown in Fig.4c. 

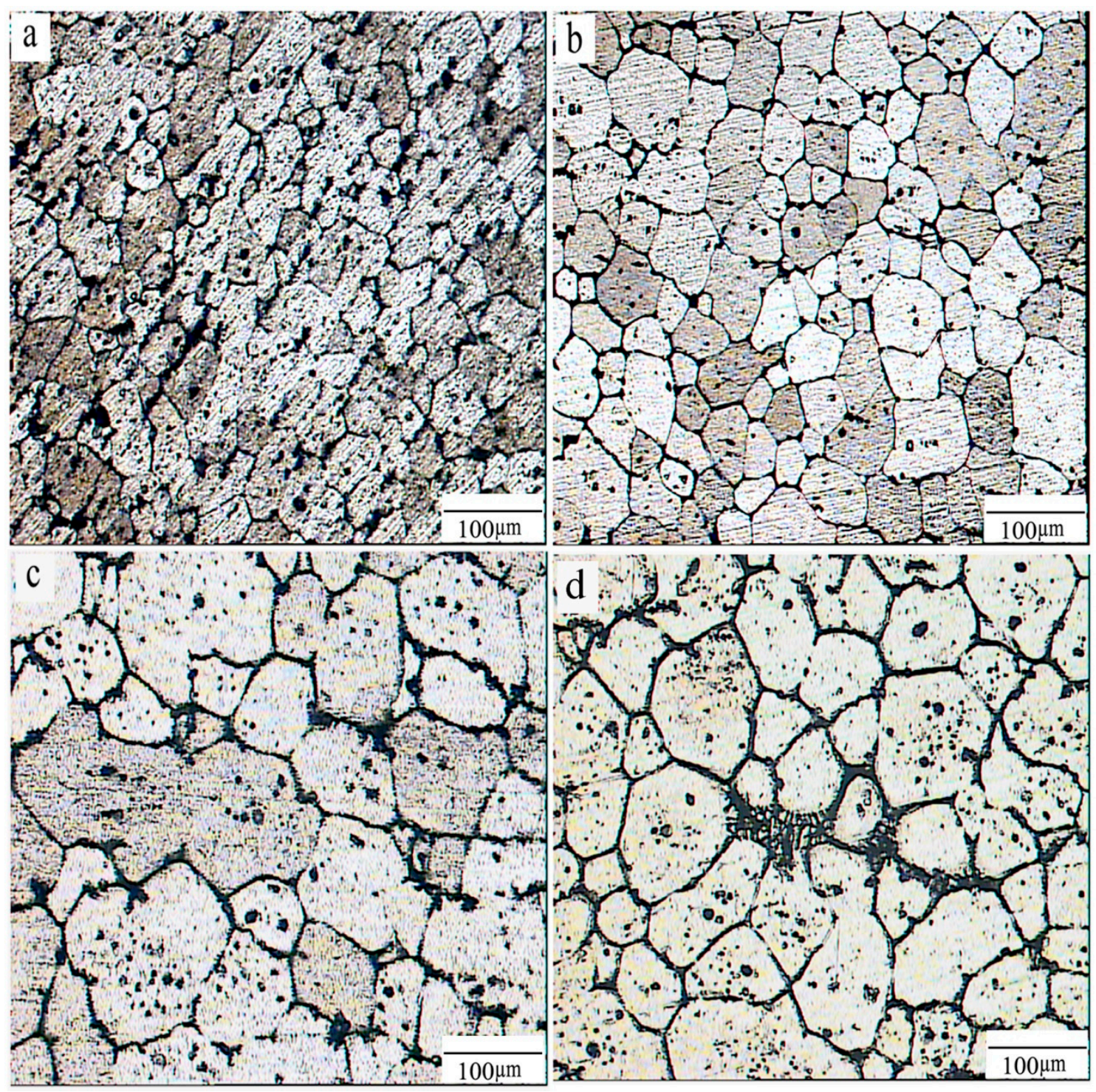

Fig. 4. Microstructures of TSSIMA samples held at $590^{\circ} \mathrm{C}$ for a) $5 \mathrm{~min}$, b) $10 \mathrm{~min}$, c) $15 \mathrm{~min}$ and d) SIMA process held at $590^{\circ} \mathrm{C}$ for $20 \mathrm{~min}$.

Fig. 5 shows variation of the average globule size and the shape factor with holding time at $590{ }^{\circ} \mathrm{C}$ after TSSIMA. With increasing the time, the average globule size decreases initially and then increases while the shape factor increases initially and then becomes fixed. The shape factor and the average globule size reach to a maximum value of 0.86 and a minimum value of $45 \mu \mathrm{m}$ for aluminum alloy in $10 \mathrm{~min}$, respectively. Therefore, the optimum grain size and shape factor were obtained for holding time of $10 \mathrm{~min}$. 


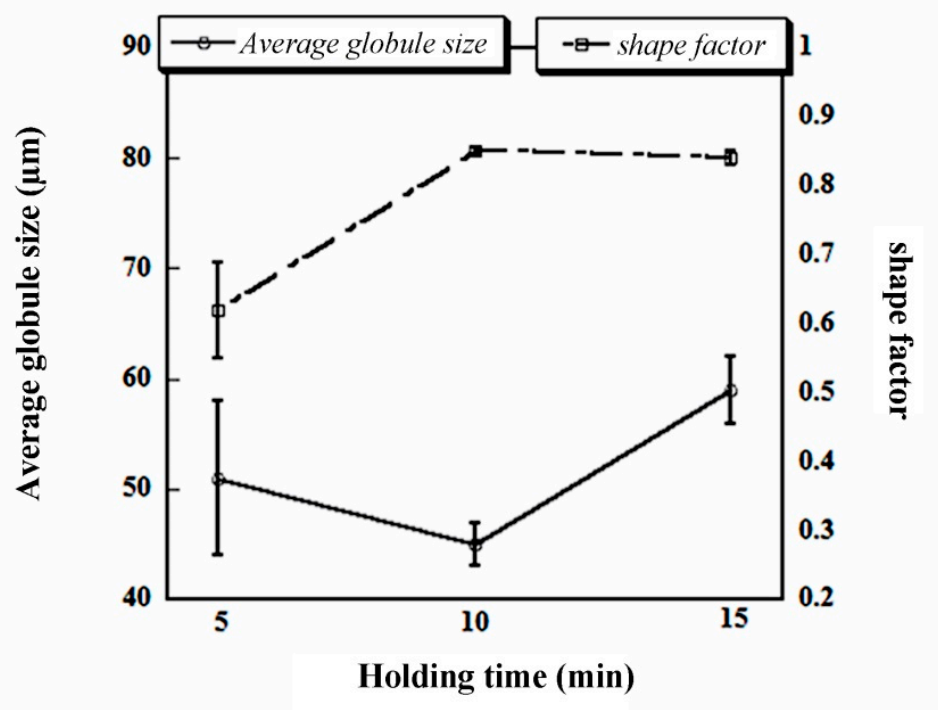

Fig. 5. Variations of average globule size and shape factor after TSSIMA with different holding time at $590{ }^{\circ} \mathrm{C}$.

It can be concluded that the whole microstructure evolution process of the predeformed alloy during heat treatment to the semi-solid state consists of four stages. First the dendrites become oriented in the same way because of the deformation. Secondly, the eutectics melt and the primary dendritic grains coarsen into the interconnected non-dendritic grains and recrystallization occurs in the non-dendritic grains. Thirdly, the eutectics melt along the primary $\alpha-\mathrm{Al}$ and the recrystallized grain boundaries and the new recrystallized grains combine and grow. Finally, the grains become separated from each other and spheroidized at the semi-solid temperature range. [16].

During heat treatment process of the specimens with adequate amount of predeformation, the solubility of the elements in $\alpha-\mathrm{Al}$ increases and $\mathrm{Al}$ and $\mathrm{Zn}$ diffuse from the eutectic phase into $\alpha$ $\mathrm{Al}$, which makes the eutectic phase to dissolve, the second arms to combine and the $\alpha$-Al to grow $[10,18]$. Because the diffusion of the atoms along the grain boundary is faster than that inside the grains, concentrations of the solute at the primary $\alpha-\mathrm{Al}$ and recrystallized grain boundary are 
higher. When the heat treatment temperature is higher than the eutectic temperature, the high concentration region begins to melt and liquid phases occur both at the grain boundaries and inside the grains $[10,18,19]$. The amount of the liquid increases and the grains separate from each other by increasing the temperature. Furthermore, due to the effect of interface curvature, spheroidization of the grains takes place in order to decrease the free energy. In addition, under the effect of interface curvature, the convex edges melt and the grains spheroidize gradually with increasing holding time. Finally, the globular microstructures favor formation of the semisolid[16]. By increasing the holding time which enhances diffusivity of the atoms in the eutectic regions [16,20], all of the above mentioned phenomena can be observed more significantly.

\subsection{Microstructure Comparison of TSSIMA with SIMA process}

An optical micrograph for the SIMA process (SIMA) is shown in Fig. 4d. According to this figure, after implementation of SIMA, deformation structure is removed and globularization of the grains occurs. The Average grain size and the shape factor of two processes have been shown in Fig. 6. By comparison of these graphs, it can be seen that the grain size in SIMA is larger than that in TSSIMA and the grain sphericity and homogeneity of TSSIMA is more than SIMA. 


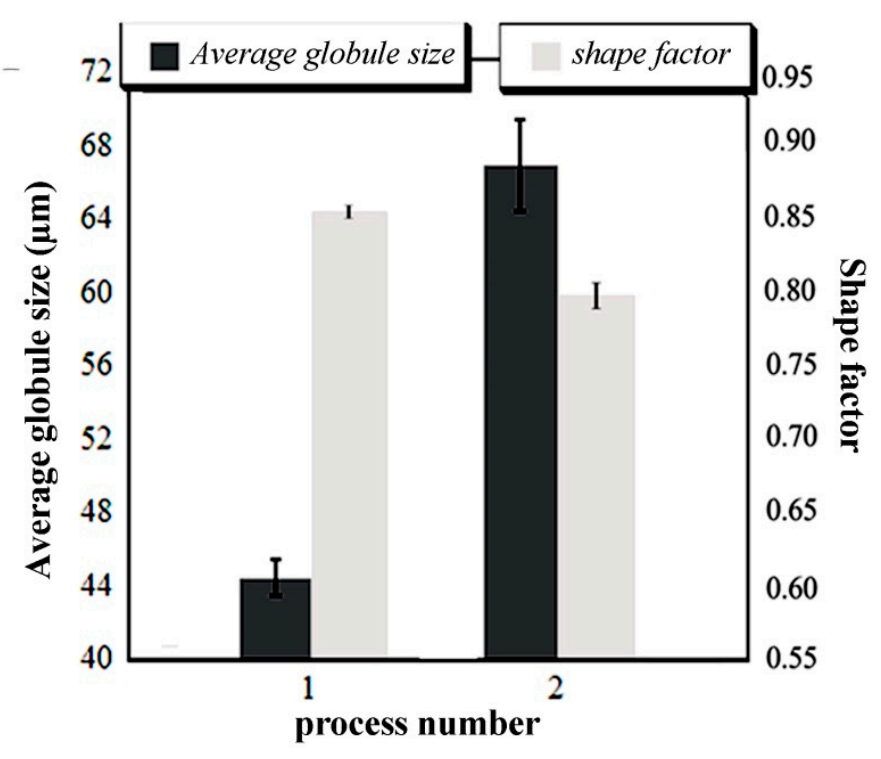

Fig. 6. Variations of average globule size and shape factor after two processes.

The SEM micrographs of processes 2 revealed a globular microstructure of primary $\alpha$ (Al) solid solution surrounded by the eutectic and the continuous secondary phases (precipitates) (Fig. 7b and c). The EDX microanalysis from the precipitates was presented in Table 2. It shows that the most probable phases which exist in the 7075 microstructure are $\mathrm{MgZn}_{2}$ and $\mathrm{Al}_{2}(\mathrm{Cu}, \mathrm{Mg})(\mathrm{B}$ and $\mathrm{C}$ regions in Fig.7). According to Refs.[21], $\mathrm{MgZn}_{2}, \mathrm{Al}_{2}(\mathrm{Cu}, \mathrm{Mg})$ and $\mathrm{Al}_{32}(\mathrm{Mg}, \mathrm{Zn})$ precipitates can exist in which atoms of elements may replace each other, which can cause nonstoichiometric composition. In SIMA, these precipitations are continuous at the grain boundaries. Additionally, in SIMA (fig. 7b), the morphology of them is coarse platelets with an interconnected and branched structure. As shown in Fig. 7c, eutectic mixtures are present at triple points of grain boundaries. 


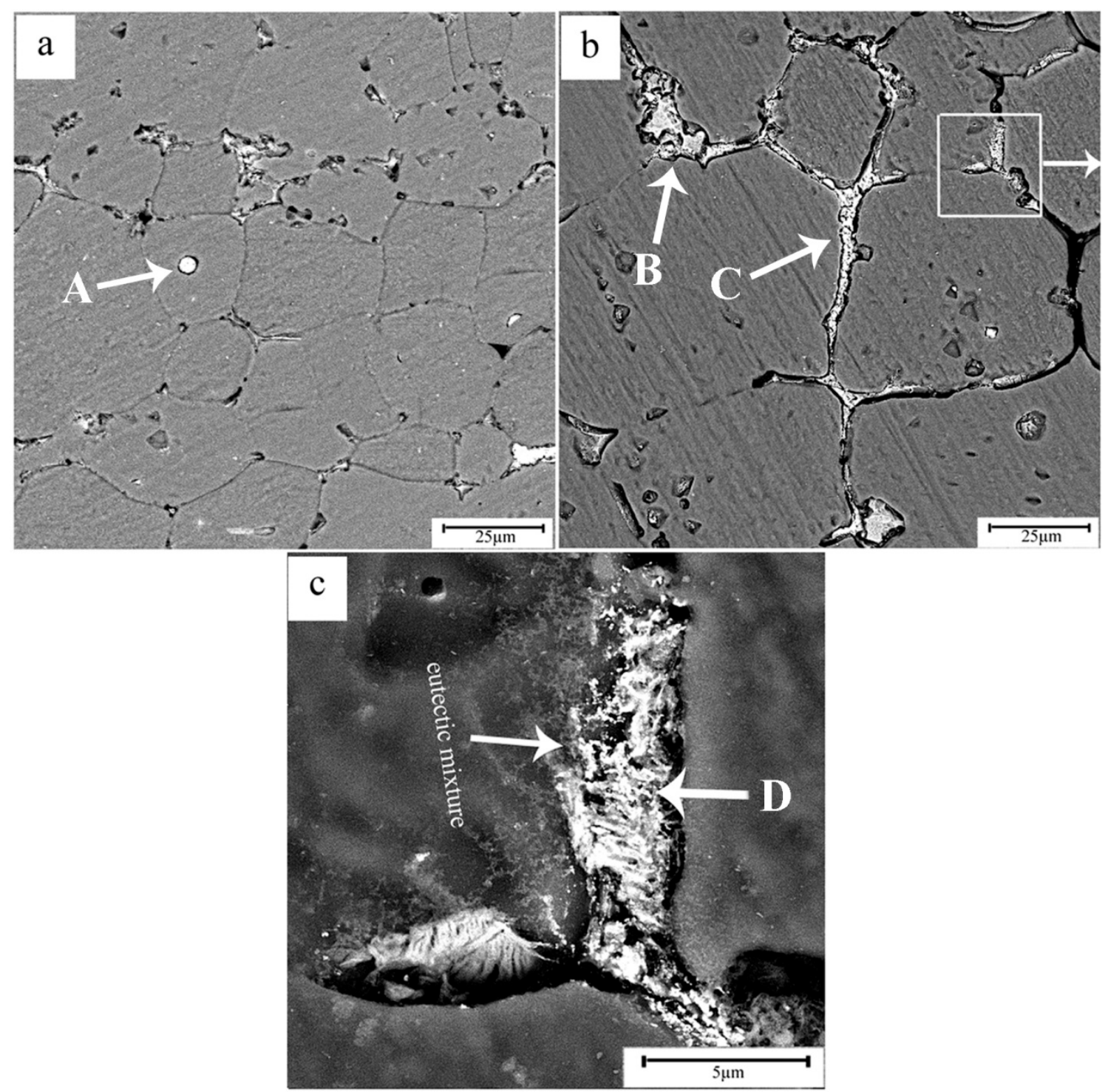

Fig. 7. SEM micrographs of specimens: a) TSSIMA, b) SIMA and c) the higher magnification of a section "b".

The EDX analysis from the eutectic structure, marked D in Fig. 7c, was presented in the Table 2. That confirmed the presence of $\mathrm{Zn}, \mathrm{Mg}, \mathrm{Cu}$ and $\mathrm{Al}$ in the eutectic mixture. It is clear that the predominant eutectic structure includes $\alpha-\mathrm{Al}$ and $\mathrm{Al}_{2}(\mathrm{Cu}, \mathrm{Mg})$ and $\eta-\mathrm{MgZn} 2$ phases. It is important to note that solubility of $\eta$-phase for copper is relatively high [14], so it can be observed in the eutectic structure with a higher concentration than $\mathrm{Zn}$. 
Table. 2. Results of EDX analysis of 7075 aluminum alloys.

\begin{tabular}{ccccccc}
\hline $\begin{array}{c}\text { Area of } \\
\text { analysis }\end{array}$ & \multicolumn{5}{c}{ Content [wt\%] } \\
\cline { 2 - 7 } & $\mathrm{Mg}$ & $\mathrm{Mn}$ & $\mathrm{Cu}$ & $\mathrm{Zn}$ & $\mathrm{Fe}$ & $\mathrm{Al}$ \\
$\mathbf{n}$ & 1.55 & 0.23 & 55.1 & 4.43 & 0.43 & 38.26 \\
B & 5.32 & 0.2 & 18.17 & 8.32 & 2.71 & 65.28 \\
C & 1.95 & 0.18 & 46.99 & 4.87 & 0 & 46.01 \\
D & 3.96 & 0.1 & 9.36 & 8.74 & 0.4 & 77.44 \\
\hline
\end{tabular}

Fig. 8 shows distribution of the major elements at the semisolid state by the line scan analysis. The peak intensity of an element shows the average concentration of the element between the horizontal lines. This image illustrates that the segregation of the solute occurred during solidification of the semi-solid alloy (SIMA) led to the high concentration of $\mathrm{Cu}, \mathrm{Mg}$ and $\mathrm{Zn}$ in the grain boundary regions. The material melts locally at the grain boundaries due to the marginally enriched alloying elements there and the associated lower solidus temperature. Content of $\mathrm{Cu}$ at the grain boundary is more than the other elements, this means that the low melting temperature structure at the grain boundary was much influenced by $\mathrm{Cu}$. 

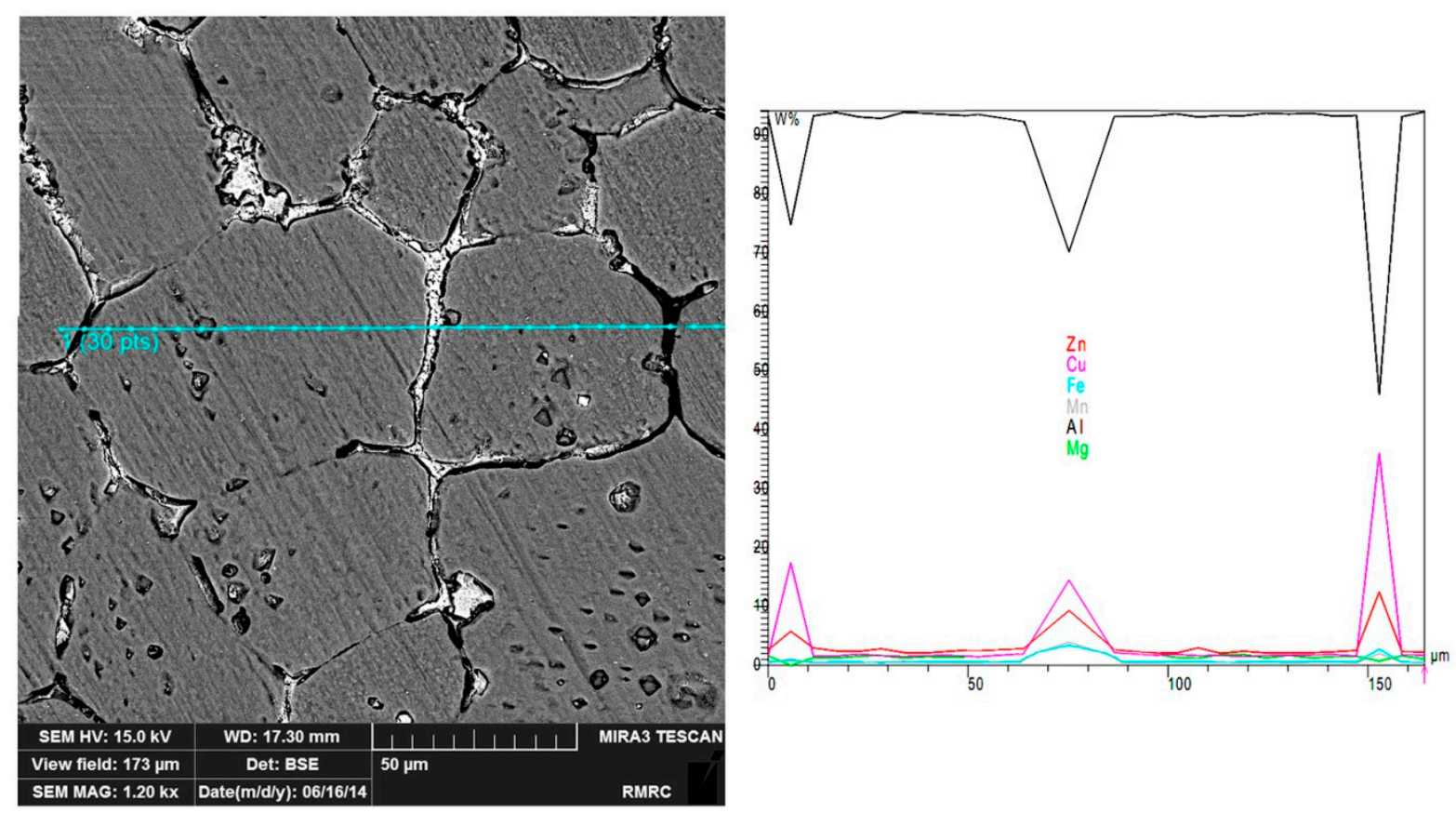

Fig. 8. Distribution of major elements in 7075 aluminum microstructure by SEM and line analysis in sample of SIMA.

Fig. 7a shows the SEM images of 7075 aluminum alloy after completion of TSSIMA. It is noticeable that this process enhances the number of the grain boundaries, reduces their thickness, promotes discontinuity and more homogeneous distribution of the precipitates and approximately removes the eutectic structure at grain boundaries. Also, small sphere-shaped $\mathrm{Al}_{2} \mathrm{Cu}$ precipitate is found out within grains. Fig. 9 illustrates the volume fraction of the precipitates in the grain boundaries. Based on that graph, TSSIMA decreases it respect to SIMA. 


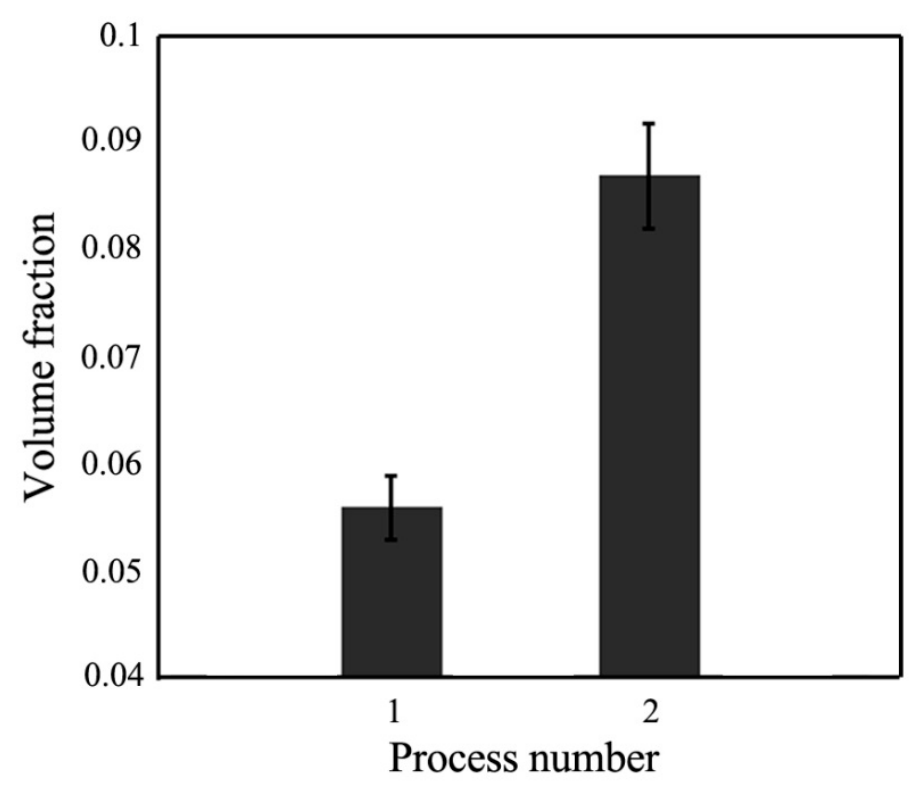

Fig. 9. volume fraction of the precipitates at grain boundaries in two processes.

EDX Analysis of the precipitates has been shown in table. 2. It is seen that the predominant ones include $\mathrm{Al}_{2}(\mathrm{Cu} / \mathrm{Mg})$ and $\mathrm{MgZn}_{2}$ phases. Also, it indicates that aluminum contents are higher than the average level of chemical composition in the alloy. In spite of more contribution of aluminum, matrix may be involved in the EDX signal of the precipitates because of its small size. Fig. $10 \mathrm{a}$ and $\mathrm{b}$ show a distribution of the major elements of TSSIMA by scanning electron microscopy and line analysis to parallel and transverse with a grain boundary, respectively. The concentrations of $\mathrm{Cu}$ and $\mathrm{Zn}$ increases in the precipitates and decreases in the other positions. this means that the precipitates have discretely located in the grain boundaries (Fig 10a). Additionally, concentration of the solutes is approximately fixed both in grains and grain boundaries without precipitates (Fig. 10b). In other words, the composition of grain and grain boundaries is similar and uniform. Furthermore, for TSSIMA, it can be seen that concentration of the solutes in the grains is similar to that of the grain boundaries (point A on Fig. 10a and point B on Fig. 10b). 

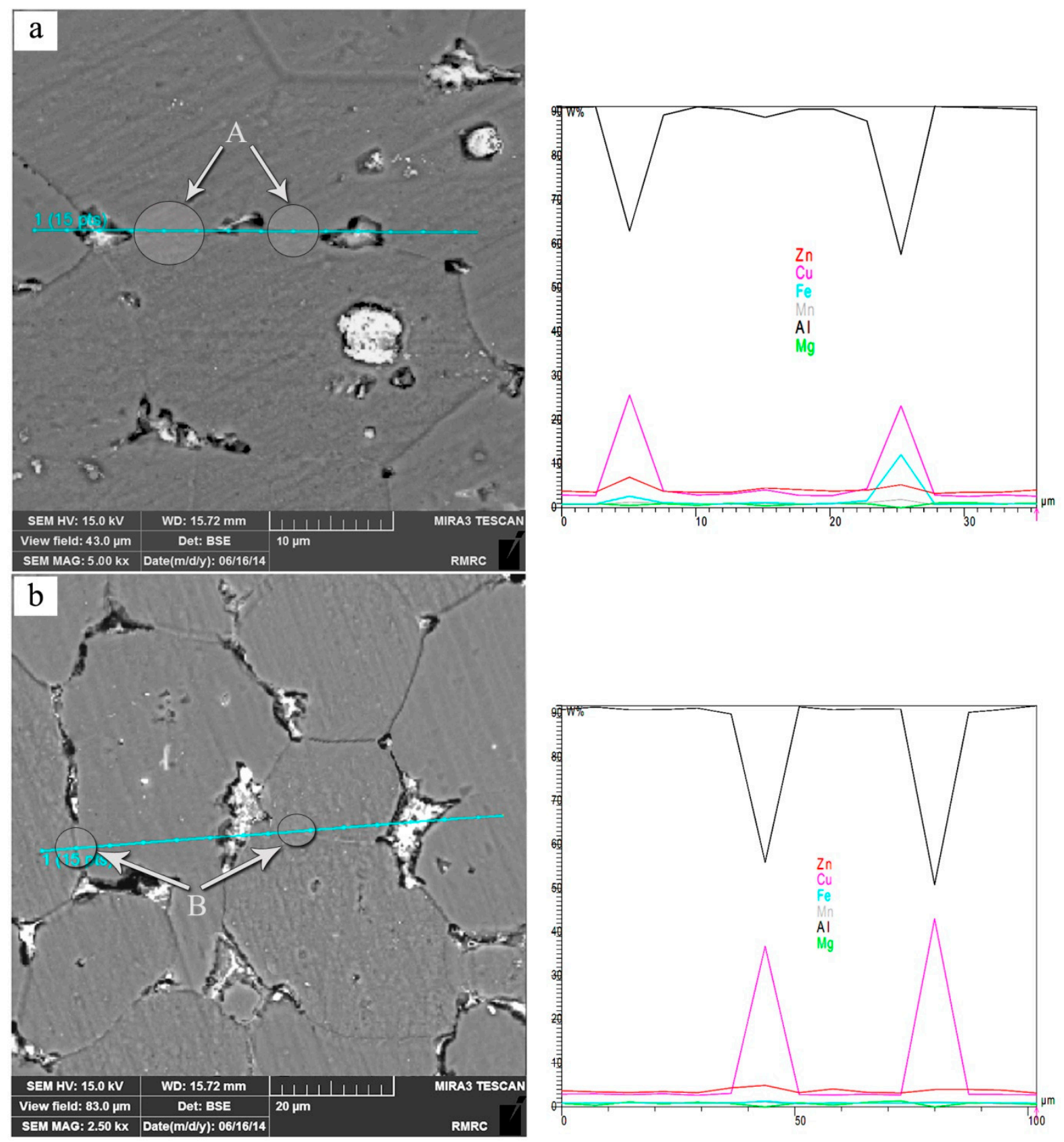

Fig. 10. Distribution of major elements in 7075 aluminum microstructure by SEM and line analysis in sample of TSSIMA: a) parallel with grain boundary and b) transverse with grain boundary.

The precipitate morphology changes resulting from the TSSIMA originate from the instability of the interface between phases. Plate-like precipitations are more unstable than the equiaxed kind. Thus, Spheroidization and discontinuity of the continuous flaky phase occur at elevated 
temperatures, because the interfacial energy of a system decreases with reduction in the interfacial surface area per unit volume of the continuous phase. The reduction in the interfacial energy is the driving force for spheroidization and discontinuity processes which are also diffusion-controlled. The degree of interconnection of the precipitates is reduced as spherical and finely dispersed particles are obtained in the aluminum matrix. Whenever, cooling rate to solid state is equilibrium, the precipitates preserve their equilibrium morphology and form spherically and discontinuous at grain boundaries.

During solidification of the SIMA process (SIMA), the low-melting-point eutectics will form at the grain boundary due to the high content of alloying element of the 7075 aluminum alloy and the non- equilibrium solidification of this process. After holding in $590{ }^{\circ} \mathrm{C}$, parts of secondary phases and the light gray net-shaped eutectics of alloy begin to dissolve into the matrix. As the holding time increases, the non-equilibrium low melting eutectics gradually dissolves and the size of residual phases gradually decreases. In TSSIMA, after dissolving eutectic structure at 590 ${ }^{\circ} \mathrm{C}$, because cooling rate $\left(590^{\circ} \mathrm{C}\right.$ to $\left.500^{\circ} \mathrm{C}\right)$ is near equilibrium conditions and diffusion in solid and liquid is complete, non-equilibrium low melting eutectics don't form at grain boundaries during cooling treatment.

\subsection{Formability}

In order to investigate formability of these two processes, all the samples were rolled after completion of each process. Fig. 11 displays the rolled specimens. In the annealed specimen, it is deformed without any crack and rupture (Fig. 11a) while after performance of the SIMA process (SIMA), it is misshaped with creation of the many cracks on its surface and even that is 
fragmented (Fig. 11b). TSSIMA (Fig. 11c) remarkably improves formability of 7075 aluminum alloy without any crack and fracture on its surface, as annealing process (Fig. 11a).

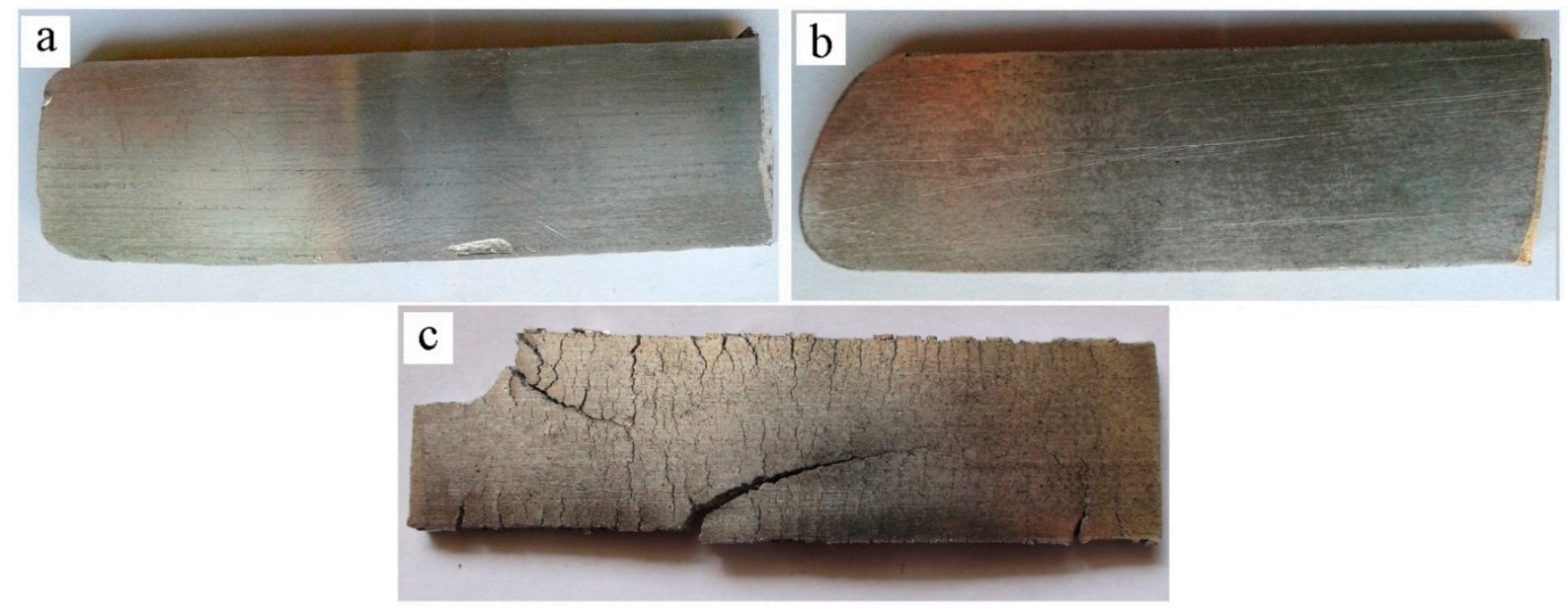

Fig. 11. Rerolled sample surface of: a) annealing process, b) TSSIMA and c) SIMA.

Mechanical properties (tensile, hardness and formability) of the 7075 aluminum alloy mainly depend on a shape, size and distribution of $\alpha$-Al grains, eutectic structures and precipitates in the structure [22]. In TSSIMA respect to SIMA process, formability improvement is due to the grain size reduction, a finer and discontinuous distribution of second phases (i.e. precipitates) and elimination of a eutectic structure at grain boundaries. It is well known that grain refinement increases strength and ductility of 7075 aluminum alloy [23]. Intermetallic compounds and eutectic structure are brittle and considered as important crack initiating sites during loading. For this reason, presence, size, morphology and continuity of them considerably affect the formability of this alloy.

\subsection{Hardness}

Fig. 12 shows the results of hardness tests. It can be seen that the hardness of the SIMA process sample was $129 \mathrm{VH}$ that increased to $149 \mathrm{VH}$ at TSSIMA. The hardness changes must 
be explained by means of the TSSIMA effects on the homogeneity of the hard precipitation in microstructure and increasing hardness of $\alpha-\mathrm{Al}$ matrix.

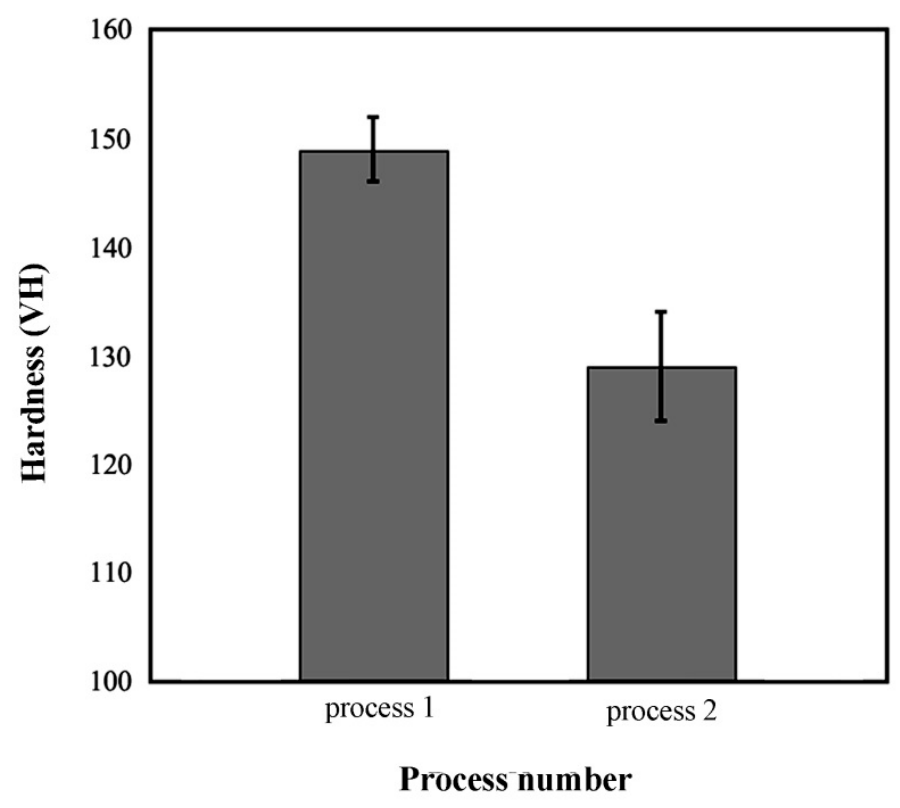

Fig. 12. Hardness test of two processes.

\section{Conclusions}

The effects of two mentioned processes on the microstructure, formability and hardness of a 7075 aluminum alloy were studied. The following conclusions can be drawn from this study:

1) In the SIMA method, although globular grains were formed, the brittle eutectic structure and intermetallic compounds were continuously created in the grain boundaries.

2) TSSIMA improved the microstructure of 7075 aluminum alloy, respect to that of SIMA procedure. In addition to creating finer globular structure, this process promoted the discontinuity and more homogeneous distribution of the precipitates. Also, that approximately removed the eutectic structure at grain boundaries. 
3) New method (TSSIMA) improved formability of 7075 aluminum alloy without the creation of any crack and fracture on the rolled surface of specimen, respect to SIMA process.

4) TSSIMA increased hardness of 7075 aluminum alloy respect to that of SIMA.

\section{Acknowledgements}

The authors would like to thank Graduate University of Advanced Technology for financial support of this research. The first author also thanks to his wife and presents this paper to her.

\section{References}

1. Jiang, H.; Li, M. Microscopic observation of cold-deformed al-4cu-mg alloy samples after semi-solid heat treatments. Materials characterization 2005, 54, 451-457.

2. Binesh, B.; Aghaie-Khafri, M. Phase evolution and mechanical behavior of the semisolid sima processed 7075 aluminum alloy. Metals 2016, 6, 42.

3. Lin, C.-W.; Hung, F.-Y.; Lui, T.-S. High-temperature compressive resistance and mechanical properties improvement of strain-induced melt activation-processed al-mg-si aluminum alloy. Metals 2016, 6, 183.

4. Basavakumar, K.; Mukunda, P.; Chakraborty, M. Influence of grain refinement and modification on microstructure and mechanical properties of al-7si and al-7si-2.5 cu cast alloys. Materials Characterization 2008, 59, 283-289.

5. Mikolajczak, P. Microstructural evolution in almgsi alloys during solidification under electromagnetic stirring. Metals 2017, 7, 89. 
6. Hernández, F.R.; Sokolowski, J. Effects and on-line prediction of electromagnetic stirring on microstructure refinement of the 319 al-si hypoeutectic alloy. Journal of Alloys and Compounds 2009, 480, 416-421.

7. Haga, T.; Suzuki, S. Casting of aluminum alloy ingots for thixoforming using a cooling slope. Journal of materials processing technology 2001, 118, 169-172.

8. Kliauga, A.; Ferrante, M. Liquid formation and microstructural evolution during reheating and partial melting of an extruded a356 aluminium alloy. Acta materialia 2005, 53, 345356.

9. Lin, C.-W.; Hung, F.-Y.; Lui, T.-S.; Chen, L.-H. Microstructure evolution and hightemperature compressibility of modified two-step strain-induced melt activation-processed almg-si aluminum alloy. Metals 2016, 6, 113.

10. Wang, J.; Lu, P.; Wang, H.; Liu, J.; Jiang, Q. Semisolid microstructure evolution of the predeformed az91d alloy during heat treatment. Journal of alloys and compounds 2005, 395, $108-112$.

11. Lashkari, O.; Ghomashchi, R. The implication of rheology in semi-solid metal processes: An overview. Journal of materials processing technology 2007, 182, 229-240.

12. Bolouri, A.; Shahmiri, M.; Kang, C. Study on the effects of the compression ratio and mushy zone heating on the thixotropic microstructure of aa 7075 aluminum alloy via sima process. Journal of Alloys and Compounds 2011, 509, 402-408. 
13. Haghdadi, N.; Zarei-Hanzaki, A.; Heshmati-Manesh, S.; Abedi, H.; Hassas-Irani, S. The semisolid microstructural evolution of a severely deformed a356 aluminum alloy. Materials \& Design 2013, 49, 878-887.

14. Mondal, C.; Mukhopadhyay, A. On the nature of t (al 2 mg 3 zn 3) and s (al 2 cumg) phases present in as-cast and annealed 7055 aluminum alloy. Materials Science and Engineering: A 2005, 391, 367-376.

15. Bolouri, A.; Shahmiri, M.; Kang, C.G. Coarsening of equiaxed microstructure in the semisolid state of aluminum 7075 alloy through sima processing. Journal of Materials Science 2012, 47, 3544-3553.

16. Alipour, M.; Emamy, M.; Ebrahimi, S.H.S.; Azarbarmas, M.; Karamouz, M.; Rassizadehghani, J. Effects of pre-deformation and heat treatment conditions in the sima process on properties of an al-zn-mg-cu alloy modified by al-8b grain refiner. Materials Science and Engineering: A 2011, 528, 4482-4490.

17. Bolouri, A.; Shahmiri, M.; Cheshmeh, E. Microstructural evolution during semisolid state strain induced melt activation process of aluminum 7075 alloy. Transactions of Nonferrous Metals Society of China 2010, 20, 1663-1671.

18. Jiang, J.; Wang, Y.; Qu, J.; Du, Z.; Sun, Y.; Luo, S. Microstructure evolution of am60 magnesium alloy semisolid slurry prepared by new sima. Journal of Alloys and Compounds 2010, 497, 62-67.

19. Zoqui, E. Morphological analysis of ssm al-4.5 wt.\% cu measured by the rheocast quality index. Journal of materials processing technology 2003, 143, 195-201. 
20. Alipour, M.; Emamy, M. Effects of al-5ti-1b on the structure and hardness of a super high strength aluminum alloy produced by strain-induced melt activation process. Materials $\&$ Design 2011, 32, 4485-4492.

21. Atkinson, H.V.; Burke, K.; Vaneetveld, G. Recrystallisation in the semi-solid state in 7075 aluminium alloy. Materials Science and Engineering: A 2008, 490, 266-276.

22. Alipour, M.; Emamy, M.; Azarbarmas, M.; Karamouz, M.; Barlat, F.; Moon, Y.; Lee, M. In Effects of al $-5 \mathrm{ti}-1 \mathrm{~b}$ master alloy on the microstructural evaluation of a highly alloyed aluminum alloy produced by sima process, AIP Conference Proceedings, 2010; AIP: pp 10601072.

23. Iwahashi, Y.; Wang, J.; Horita, Z.; Nemoto, M.; Langdon, T.G. Principle of equalchannel angular pressing for the processing of ultra-fine grained materials. Scripta materialia $1996,35,143-146$. 